\title{
Photoelectrochemical Gas-Electrolyte-Solid Phase Boundary for Hydrogen Production From Water Vapor
}

\author{
Fumiaki Amano ${ }^{1,2 *}$, Ayami Shintani ${ }^{1}$, Hyosuke Mukohara ${ }^{1}$, Young-Min Hwang ${ }^{1}$ and \\ Kenyou Tsurui ${ }^{1}$
}

${ }^{1}$ Department of Chemical and Environmental Engineering, The University of Kitakyushu, Kitakyushu, Japan, ${ }^{2}$ Precursory Research for Embryonic Science and Technology (PRESTO), Japan Science and Technology Agency (JST), Kawaguchi, Japan

Hydrogen production from humidity in the ambient air reduces the maintenance costs for sustainable solar-driven water splitting. We report a gas-diffusion porous photoelectrode

OPEN ACCESS

Edited by:

Steve Suib,

University of Connecticut,

United States

Reviewed by:

Chang-Yong Nam,

Brookhaven National Laboratory

(DOE), United States

Christoph Richter,

Deutsches Zentrum für Luft- und Raumfahrt, Helmholtz-Gemeinschaft Deutscher Forschungszentren ( $H Z)$,

Germany

${ }^{*}$ Correspondence:

Fumiaki Amano

amano@kitakyu-u.ac.jp

Specialty section

This article was submitted to Green and Sustainable Chemistry, a section of the journal

Frontiers in Chemistry

Received: 13 October 2018 Accepted: 19 November 2018 Published: 03 December 2018

Citation:

Amano F, Shintani A, Mukohara H, Hwang Y-M and Tsurui K (2018)

Photoelectrochemical

Gas-Electrolyte-Solid Phase

Boundary for Hydrogen Production

From Water Vapor

Front. Chem. 6:598.

doi: 10.3389/fchem.2018.00598 consisting of tungsten trioxide $\left(\mathrm{WO}_{3}\right)$ nanoparticles coated with a proton-conducting polymer electrolyte thin film for visible-light-driven photoelectrochemical water vapor splitting. The gas-electrolyte-solid triple phase boundary enhanced not only the incident photon-to-current conversion efficiency (IPCE) of the $\mathrm{WO}_{3}$ photoanode but also the Faraday efficiency (FE) of oxygen evolution in the gas-phase water oxidation process. The IPCE was $7.5 \%$ at an applied voltage of $1.2 \mathrm{~V}$ under $453 \mathrm{~nm}$ blue light irradiation. The FE of hydrogen evolution in the proton exchange membrane photoelectrochemical cell was close to $100 \%$, and the produced hydrogen was separated from the photoanode reaction by the membrane. A comparison of the gas-phase photoelectrochemical reaction with that in liquid-phase aqueous media confirmed the importance of the triple phase boundary for realizing water vapor splitting.

Keywords: gas-phase water splitting, solar $\mathrm{H}_{2}$ production, visible-light-driven photoelectrode, tungsten oxide photoanode, proton exchange membrane

\section{INTRODUCTION}

Large-scale deployment of photocatalytic and photoelectrochemical (PEC) water-splitting technologies, accompanied by fuel cells and energy carrier technologies, will allow the realization of the hydrogen $\left(\mathrm{H}_{2}\right)$ economy (Maeda and Domen, 2010). Separation of $\mathrm{H}_{2}$ and oxygen $\left(\mathrm{O}_{2}\right)$ is easily achieved in PEC systems that use solid polymer electrolyte membranes (Pinaud et al., 2013; McKone et al., 2014). Laboratory-scale PEC studies are usually performed in aqueous electrolyte solutions using purified water without contamination. However, in practice, water resources are an issue for solar $\mathrm{H}_{2}$ production. Stable supply of water might be problematic for large-scale solar $\mathrm{H}_{2}$ production owing to limited rainfall in areas with low-cost land and abundant solar radiation such as deserts (Kumari et al., 2016). Another possible feedstock is seawater, but its use requires purification to avoid problems such as corrosion, poisoning, fouling, and byproduct formation. In contrast, gaseous water has been proposed as an attractive alternative to liquid water because an inexhaustible supply of water vapor from the ambient humid air is available at sea with high relative humidity $(\sim 80 \%)$ (Kumari et al., 2016). Gas-phase operations can significantly decrease maintenance costs because the natural convection of air can be used to feed the water vapor and 
systems to purify and pump liquid water are not required (Rongé et al., 2014; Modestino et al., 2015).

Gas-phase water splitting by all-solid PEC systems has been studied using proton exchange membranes (PEMs) as a solid polymer electrolyte and n-type semiconductor electrodes as a photoanode (Georgieva et al., 2009, 2010; Iwu et al., 2013; Rong et al., 2013; Tsui et al., 2013; Rongé et al., 2014; Stoll et al., 2016, 2017; Verbruggen et al., 2017). PEC water oxidation is induced by photogenerated holes on the photoanode, which is in contact with the membrane, whereas the $\mathrm{H}_{2}$ evolution reaction occurs on the cathode, which is located on the opposite side of the membrane. The PEM-based photoelectrolyzer (PEM-PEC cell) can be operated using gas-phase reactants such as water vapor and volatile organic compounds in air. However, the photon-to-current conversion efficiencies of the photoanodes are frequently low owing to the difficulties associated with designing electrodes for "gas-solid" PEC systems in contrast to those for conventional "liquid-solid" systems in aqueous electrolytes. The photoelectrode for a gas-phase reaction should exhibit gas diffusion properties for mass transport and proton conductivity for ion transport toward the membrane. It has been proposed that high-surface-area photoanodes need to be covered with a polymer electrolyte thin film to maximize the gas-electrolytesolid phase contact area (Spurgeon and Lewis, 2011; Xiang et al., 2016). However, the effect of such a triple phase boundary has not been elucidated for gas-solid PEC systems. In addition, most studies have focused on $\mathrm{TiO}_{2}$-based photoanodes under UV irradiation, and there are only a few reports on visible-lightresponsive photoelectrodes for gas-phase reactions (Georgieva et al., 2009; Stoll et al., 2017). The use of narrow band gap semiconductors is necessary to achieve high solar-to-hydrogen efficiency because the number of photons is limited in the UV range. The maximum solar-to-hydrogen efficiency is only $1.7 \%$ even if all the UV light with wavelength shorter than $400 \mathrm{~nm}$ is utilized for water splitting reaction under AM1.5G spectrum (Abe, 2010; Hisatomi et al., 2015).

The aim of this study was to develop an all-solid PEC system with a triple phase boundary for water vapor splitting under visible-light irradiation. We selected tungsten trioxide $\left(\mathrm{WO}_{3}\right)$ as a blue-light responsive semiconductor with a narrow band gap of 2.6-2.7 eV (Amano et al., 2013). High-surface-area $\mathrm{WO}_{3}$ nanoparticles were deposited on porous titanium microfiber felt $\left(\mathrm{WO}_{3} / \mathrm{Ti}\right.$ fiber), which was then covered with a perfluorosulfonic acid ionomer electrolyte thin film to improve its proton transport properties. The perfluorosulfonate ionomer, DuPont Nafion ${ }^{\circledR}$, exhibits good proton conductivity at room temperature in hydrous conditions (Kusoglu and Weber, 2017). The Nafion ionomer thin film also has high chemical stability, moderate gas permeability, and moisture absorbency, which allows it to capture humidity in the gas phase (Modestino et al., 2015). We fabricated a membrane electrode assembly (MEA) by hot pressing the $\mathrm{WO}_{3} /$ Ti-fiber electrode onto a PEM with a platinum catalyst film on the opposite side. The effect of the ionomer thin film loading on the PEC performances of the $\mathrm{WO}_{3} / \mathrm{Ti}$ fiber electrode was investigated in both humidified argon and liquid water using two-electrode and conventional three-electrode configurations.

\section{MATERIALS AND METHODS Preparation of $\mathrm{WO}_{3}$ Gas Diffusion Electrode}

Sintered Ti microfiber felt (thickness: $0.1 \mathrm{~mm}$, Nikko Techno, Japan) was used as a macroporous conductive substrate to prepare a gas diffusion electrode composed of $\mathrm{WO}_{3}$ nanoparticles (Homura et al., 2014; Amano et al., 2017). Ammonium metatungstate hydrate (20.4 g, Nippon Inorganic Colour \& Chemical, Japan) and PEG 20,000 (10.0 g, Wako Pure Chemical, Japan) were dissolved in deionized water $(40.0 \mathrm{~g})$ as a solution for dip coating of the Ti microfiber felt. The dip coating process was performed three times. The precursor-coated Ti microfiber felt was dried at $353 \mathrm{~K}$ and calcined in air at $923 \mathrm{~K}$ for $2 \mathrm{~h}$ to achieve crystallization of $\mathrm{WO}_{3}$. If required, the obtained $\mathrm{WO}_{3} / \mathrm{Ti}$ fiber electrode was treated with a Nafion ${ }^{\circledR}$ perfluorosulfonic acid (PFSA) ionomer dispersion (5 wt\% in mixture of lower aliphatic alcohols and water, contains $45 \%$ water, Sigma-Aldrich Japan, Japan) as a proton-conducting polymer. The dispersion was dropped on the electrode $\left(10 \mu \mathrm{L} \mathrm{cm}{ }^{-2}\right)$, and the wetted electrode was dried at $353 \mathrm{~K}$. The loading amount of the Nafion ionomer was $\sim 0.6 \mathrm{mg} \mathrm{cm}^{-2}$.

\section{Preparation of Membrane Electrode Assembly}

A carbon black-supported platinum nanoparticles $(\mathrm{Pt} / \mathrm{CB})$ was used as a cathode catalyst for $\mathrm{H}_{2}$ evolution. A cathode catalyst ink was prepared by ultrasonication of a mixture of a $\mathrm{Pt} / \mathrm{CB}$ (TEC10E50E, Pt loading: 46.6 wt\%, Tanaka Kikinzoku Kogyo, Japan) and the Nafion ionomer dispersion. The weight ratio of the Nafion ionomer to $\mathrm{Pt}$ was adjusted to 1.0, and the loading amount of platinum was $\sim 0.1 \mathrm{mg} \mathrm{cm} \mathrm{cm}^{-2}$. The ionomer-mixed $\mathrm{Pt} / \mathrm{CB}$ film and the $\mathrm{WO}_{3} /$ Ti fiber electrode were hot pressed onto a Nafion membrane N117 (thickness: $183 \mu \mathrm{m}$, DuPont, USA) at $15 \mathrm{kN}$ and $413 \mathrm{~K}$. The composition of the MEA was " $\mathrm{WO}_{3} / \mathrm{Ti}$ fiber | Nafion membrane | ionomer-mixed Pt/CB."

\section{Characterization}

Scanning electron microscopy (SEM) observation and energy dispersive X-ray spectroscopy (EDS) analysis were performed on a JSM-7800F microscope (JEOL, Japan). The electrode was directly deposited on carbon tape. High-magnification SEM observation was performed on S-5200 microscope (Hitachi, Japan) with an operating voltage of $5 \mathrm{kV}$. Before the highmagnification observation, the sample deposited on carbon tape was coated with gold using an E-1030 ion sputter coater (Hitachi, Japan).

Nitrogen adsorption isotherms were recorded at $77 \mathrm{~K}$ in the relative pressure range between 0.05 and 0.30 with a BELSORPmini system (MicrotracBEL, Japan). Before the measurements, the electrode was outgassed at $473 \mathrm{~K}$ for $2 \mathrm{~h}$. The BrunauerEmmett-Teller (BET) equation was used to calculate the surface area of $\mathrm{WO}_{3} / \mathrm{Ti}$ fiber electrode. The BET specific surface area of the $\mathrm{WO}_{3}$ particles was estimated from the measured surface area of the electrode and the loading amount of the $\mathrm{WO}_{3}$ particles. The BET specific surface area of Ti microfibers was smaller than the measurement limit. 


\section{Photoelectrochemical Measurements}

The PEC reaction was conducted at room temperature (298 K) and atmospheric pressure $(0.1 \mathrm{MPa})$. The gas-phase water splitting reaction was performed using a dual compartment stainless-steel PEC reactor with an optical window, as shown in Figure 1. The compartments were separated by the Nafion membrane. Water vapor (3 vol\%) was introduced into each compartment by passing argon at a flow rate of $20 \mathrm{~mL} \mathrm{~min}-1$ through a bubbler filled with deionized water. The electrode area was $25 \mathrm{~cm}^{2}$, but the light irradiation area was $16 \mathrm{~cm}^{2}$ owing to the presence of a gold-coated copper plate as the current collector. Photoirradiation was performed using $3 \mathrm{~W}$ blue light-emitting diode lamps. The emission was centered at a wavelength $(\lambda)$ of $453 \mathrm{~nm}$ with a full width at half maximum of $22 \mathrm{~nm}$. The optical power was measured to be $\sim 7 \mathrm{~mW} \mathrm{~cm}^{-2}$. A $300 \mathrm{~W}$ xenon lamp with bandpass filters (bandwidth $\sim 10 \mathrm{~nm}$ ) was used to obtain the action spectrum for the incident photon-to-current conversion efficiency (IPCE), which is the ratio of the number of electric charges to the number of incident photons, as shown in equation (1).

$$
\operatorname{IPCE}=\left(i_{\text {photo }} \times 1240 / \lambda\right) / I_{0}
$$

where $i_{\text {photo }}$ is the steady-state photocurrent density [ $\mathrm{mA} \mathrm{cm}^{-2}$ ], $1240 / \lambda$ is the monochromatic photon energy $[\mathrm{eV}]$, and $I_{0}$ is the power of the incident monochromatic light $\left[\mathrm{mW} \mathrm{cm}^{-2}\right]$. The Faraday efficiency (FE), also known as the current efficiency, was calculated from the ratio of the electric current required for the formation of a product to the total electric current, as shown in equation (2).

$$
\mathrm{FE}=\left(n_{\mathrm{e}} \times F \times r(x)\right) / i_{\text {photo }}
$$

where $n_{\mathrm{e}}$ is the number of electrons required to form a product, $F$ is the Faraday constant, and $r(x)$ is the formation rate of product $x$. The amounts of evolved $\mathrm{O}_{2}$ and $\mathrm{H}_{2}$ were analyzed using an online gas chromatograph equipped with a thermal conductivity detector and an MS-5A column with argon as the carrier gas. The $n_{\mathrm{e}}$ values of $\mathrm{H}_{2}$ and $\mathrm{O}_{2}$ are 2 and 4, respectively.

An H-type dual compartment glass reactor was used for the PEC measurements of small area electrodes (light irradiation area: $1 \mathrm{~cm}^{2}$ ). The compartment separated by the Nafion membrane was filled with 3 vol\% $\mathrm{H}_{2} \mathrm{O}$ vapor in argon or an aqueous electrolyte of $0.1 \mathrm{~mol} \mathrm{~L}^{-1}$ sulfuric acid $(\mathrm{pH}=1)$. A silver/silver chloride $(\mathrm{Ag} / \mathrm{AgCl})$ reference electrode $(+195 \mathrm{mV}$ vs. the standard hydrogen electrode) was used in the three-electrode configuration. The Nernst equation [equation (3)] can be used to convert the electrode potential vs. $\mathrm{Ag} / \mathrm{AgCl}\left(E_{\mathrm{Ag} / \mathrm{AgCl}}\right)$ to the potential vs. the reversible hydrogen electrode $\left(E_{\mathrm{RHE}}\right)$.

$$
E_{\mathrm{RHE}}=E_{\mathrm{Ag} / \mathrm{AgCl}}+0.059 \mathrm{pH}+0.195
$$

\section{RESULTS}

\section{Preparation of the lonomer-Coated $\mathrm{WO}_{3}$ Photoelectrode}

To allow for gas diffusion and ion transport, the PEM-based PEC cell for gaseous reactants requires a three-dimensional porous electrode rather than a conventional planar dense electrode. We used a titanium microfiber felt that has a high porosity $(67 \%)$ owing to its three-dimensional fibrous structures with diameters of $20 \mu \mathrm{m}$ (Amano et al., 2017). The specific surface area of the Ti microfiber felt with a thickness of $0.1 \mathrm{~mm}$ was $\sim 450 \mathrm{~cm}^{2}$ $\mathrm{g}^{-1}$, which is 90 times larger than that of a conventional twodimensional Ti sheet with a thickness of $1.0 \mathrm{~mm}\left(5 \mathrm{~cm}^{2} \mathrm{~g}^{-1}\right)$. The formation of a highly crystalline monoclinic $\mathrm{WO}_{3}$ phase was confirmed by X-ray diffraction and Raman spectroscopy (Amano et al., submitted). The loading amount of $\mathrm{WO}_{3}$ was $13 \mathrm{mg} \mathrm{cm}^{-2}$, which corresponds to $27 \mathrm{wt} \%$ in the $\mathrm{WO}_{3} / \mathrm{Ti}$ fiber electrode. SEM images of the $\mathrm{WO}_{3} /$ Ti fiber after gold sputtering (Figure 2A) revealed that monoclinic $\mathrm{WO}_{3}$ formed nanoparticles with particle diameters of $\sim 100 \mathrm{~nm}$. The BET specific surface area of the $\mathrm{WO}_{3}$ particles was measured to be $7.5 \mathrm{~m}^{2} \mathrm{~g}^{-1}$, which corresponds to the average diameter of $110 \mathrm{~nm}$ assuming that each particle was a sphere. The estimated particle size was similar to that of the $\mathrm{WO}_{3}$ particles observed in SEM images. The PEC performance for water oxidation was tested in a conventional aqueous electrolyte solution (phosphate buffer, $\mathrm{pH}=2.2$ ). The performance of the $\mathrm{WO}_{3} / \mathrm{Ti}$ fiber electrode was superior to that of a $\mathrm{WO}_{3}$ particle electrode obtained by deposition of $\mathrm{WO}_{3}$ nanoparticles on a two-dimensional substrate such as transparent conductive oxide-coated glass and a titanium sheet (Amano et al., 2017). The IPCE of the $\mathrm{WO}_{3} /$ Ti fiber electrode was $\sim 60 \%$ at $1.0 \mathrm{~V}$ vs. $\mathrm{Ag} / \mathrm{AgCl}$ under $\mathrm{UV}$ irradiation, and the $\mathrm{FE}$ of $\mathrm{O}_{2}$ evolution was higher than $70 \%$.

A Nafion ionomer dispersion was cast on the high-surfacearea $\mathrm{WO}_{3}$ nanoparticle electrode. Figure 2B shows a highmagnification SEM image of the $\mathrm{WO}_{3} / \mathrm{Ti}$ fiber electrode after gold sputtering. The sputtered gold nanoparticles were clearly observed in the case of the ionomer-coated $\mathrm{WO}_{3} / \mathrm{Ti}$ fiber, suggesting that the Nafion ionomer thin film induced the heterogeneous nucleation of the gold nanoparticles. This phenomenon would be a useful method to visualize the Nafion ionomer thin film in SEM observation. We found that the thin film covered the $\mathrm{WO}_{3}$ particles, with some of the ionomer aggregated at the grain boundary. The thickness of the ionomer thin film was estimated to be $\sim 3 \mathrm{~nm}$ by using the specific gravity of the Nafion membrane (1.98) assuming that the thin layer uniformly covers the surface of the $\mathrm{WO}_{3}$ nanoparticles. EDS elemental analysis confirmed an increase in the content of carbon and fluorine after ionomer coating. The fluorine mapping shows that the ionomer was dispersed on the macroporous electrode, with some of the ionomer segregated in the void spaces of the Ti microfibers (Figure 2C). The ionomer-coated $\mathrm{WO}_{3} / \mathrm{Ti}$ fiber photoanode $\left(5 \times 5 \mathrm{~cm}^{2}\right)$ and an ionomer-mixed Pt/CB cathode $\left(5 \times 5 \mathrm{~cm}^{2}\right)$ were pressed on both sides of a Nafion membrane $\left(8 \times 8 \mathrm{~cm}^{2}\right)$ to fabricate an MEA for a large stainless-steel PEC reactor (irradiated area: $16 \mathrm{~cm}^{2}$ ).

\section{Gas-Phase Water Splitting in the PEM-PEC Reactor}

Figure $3 \mathrm{~A}$ shows the photoresponse of the $\mathrm{WO}_{3} / \mathrm{Ti}$ fiber photoanode with and without the ionomer in an argon flow with 3 vol\% $\mathrm{H}_{2} \mathrm{O}$ vapor (relative humidity: $\sim 90 \%$ ) under chopped 
A

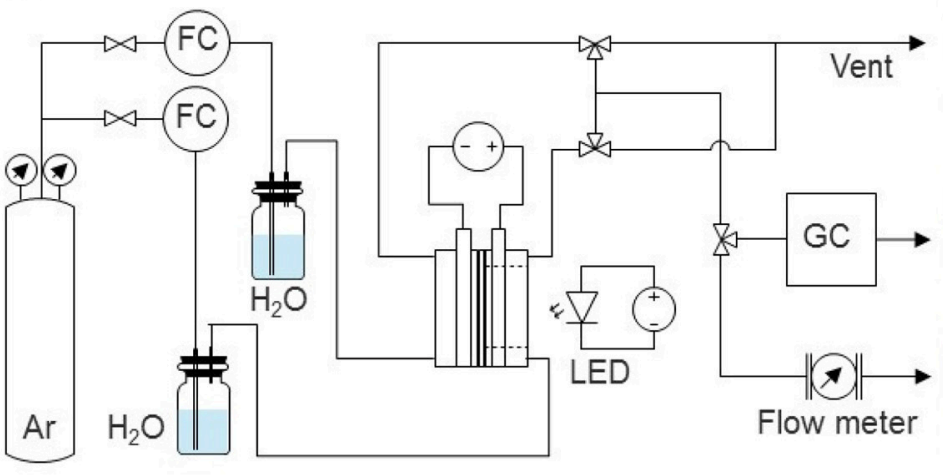

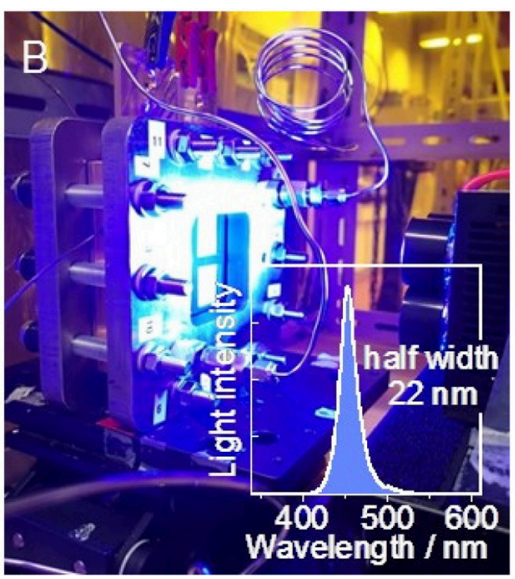

FIGURE 1 | Process flow for photoelectrolysis of water vapor (FC, flow controller; LED, light-emitting diode; GC, gas chromatograph). (B) Photograph of the photoelectrolyzer and blue LED (inset: spectrum of the blue light, centered at $453 \mathrm{~nm}$ ).
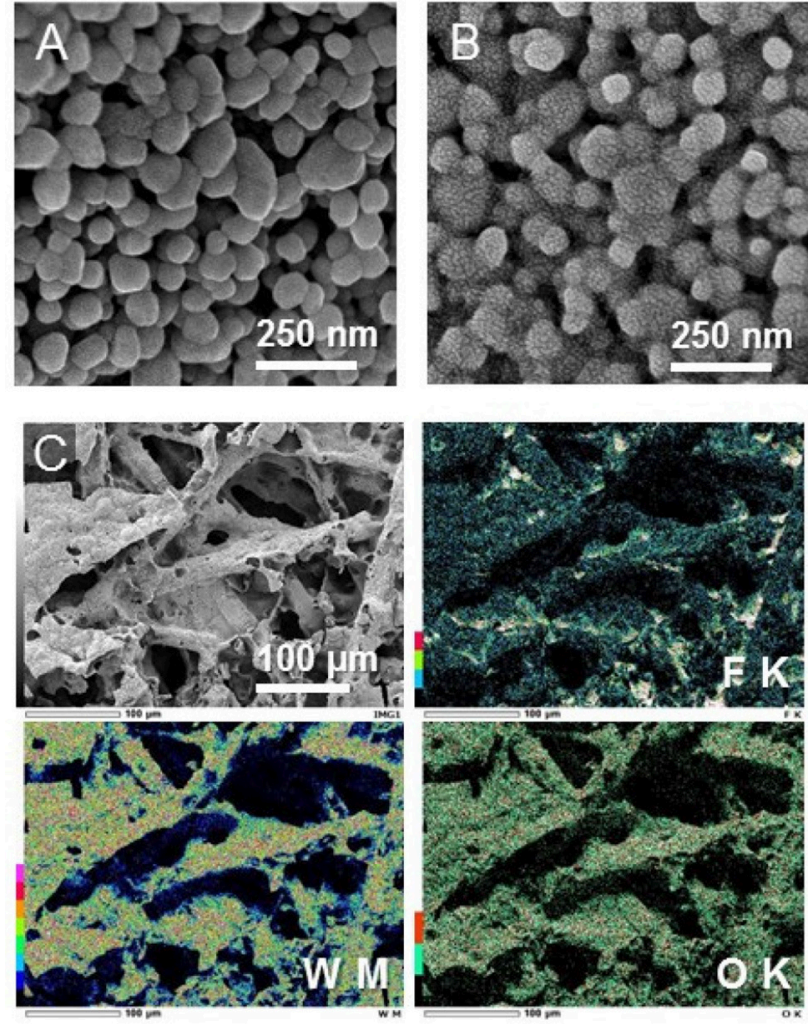

FIGURE 2 | SEM images of (A) the bare $\mathrm{WO}_{3} / \mathrm{Ti}$ fiber electrode and (B) the ionomer-coated $\mathrm{WO}_{3} / \mathrm{Ti}$ fiber electrode. The images were obtained after sputtering with gold. (C) EDS mapping images for F, W, and O elements of the ionomer-coated $\mathrm{WO}_{3} / \mathrm{Ti}$ fiber electrode.

visible-light irradiation $(\lambda=453 \mathrm{~nm})$. The two compartments of the large PEM-PEC cell were pre-purged with water vapor for more than $1 \mathrm{~h}$. The applied voltage corresponds to the potential difference between the $\mathrm{WO}_{3} / \mathrm{Ti}$ fiber photoanode and the ionomer-mixed $\mathrm{Pt} / \mathrm{CB}$ cathode. The $\mathrm{WO}_{3} / \mathrm{Ti}$ fiber electrode without the ionomer coating exhibited small photocurrent and a slow photoresponse during the gas-phase PEC measurements. The photocurrent was significantly decreased compared with that observed for the PEC performance test in a conventional aqueous electrolyte solution. In contrast, the ionomer-coated $\mathrm{WO}_{3} / \mathrm{Ti}$ fiber electrode showed an increased photocurrent response in the gas-phase PEC measurements. The photocurrent at applied voltages higher than $0.2 \mathrm{~V}$ quickly increased when the UV light was turned on, and quickly decayed to the dark current level when the light was turned off. Thus, we found that the photoresponse of the $\mathrm{WO}_{3} / \mathrm{Ti}$ fiber photoanode was accelerated by the Nafion ionomer coating, indicating that the electron transfer from water to $\mathrm{WO}_{3}$ was accelerated. Figure 3B shows the time course of the photocurrent at $1.2 \mathrm{~V}$. A Faraday current was not observed at steady state in the dark. The IPCE at $1.2 \mathrm{~V}$ was $7.6 \%$ for the ionomer-coated $\mathrm{WO}_{3} /$ Ti fiber photoanode, but the IPCE was only $3.8 \%$ in the absence of the ionomer coating. Moreover, an anodic current owing to water vapor oxidation was observed only under photoirradiation. Thus, the Nafion ionomer coating enhanced the steady-state photocurrent of the $\mathrm{WO}_{3} / \mathrm{Ti}$ fiber electrode.

Figure 4 shows the outcome of the visible-light-induced gas-phase water-splitting reaction in the PEM-PEC reactor. The applied voltage was set to $1.2 \mathrm{~V}$, which is less than the thermodynamic minimum voltage required for water electrolysis at room temperature $(1.23 \mathrm{~V})$. The reaction was repeated twice to check the evolved gasses in the photoanode and cathode compartments individually. In the first run, we analyzed the gas evolved from the cathode compartment. We detected continuous $\mathrm{H}_{2}$ formation over the ionomer-mixed $\mathrm{Pt} / \mathrm{CB}$ catalyst cathode when the photoanode was irradiated with blue light. The $\mathrm{H}_{2}$ production rate in the cathode compartment was consistent with half of the electron flow in the outer circuit $\left(\mathrm{e}^{-} / 2\right)$. The $\mathrm{FE}$ of $\mathrm{H}_{2}$ evolution was close to $100 \%$, assuming a two-electron reaction $\left(2 \mathrm{H}^{+}+2 \mathrm{e}^{-} \rightarrow \mathrm{H}_{2}\right)$. This result indicates that the photoexcited 

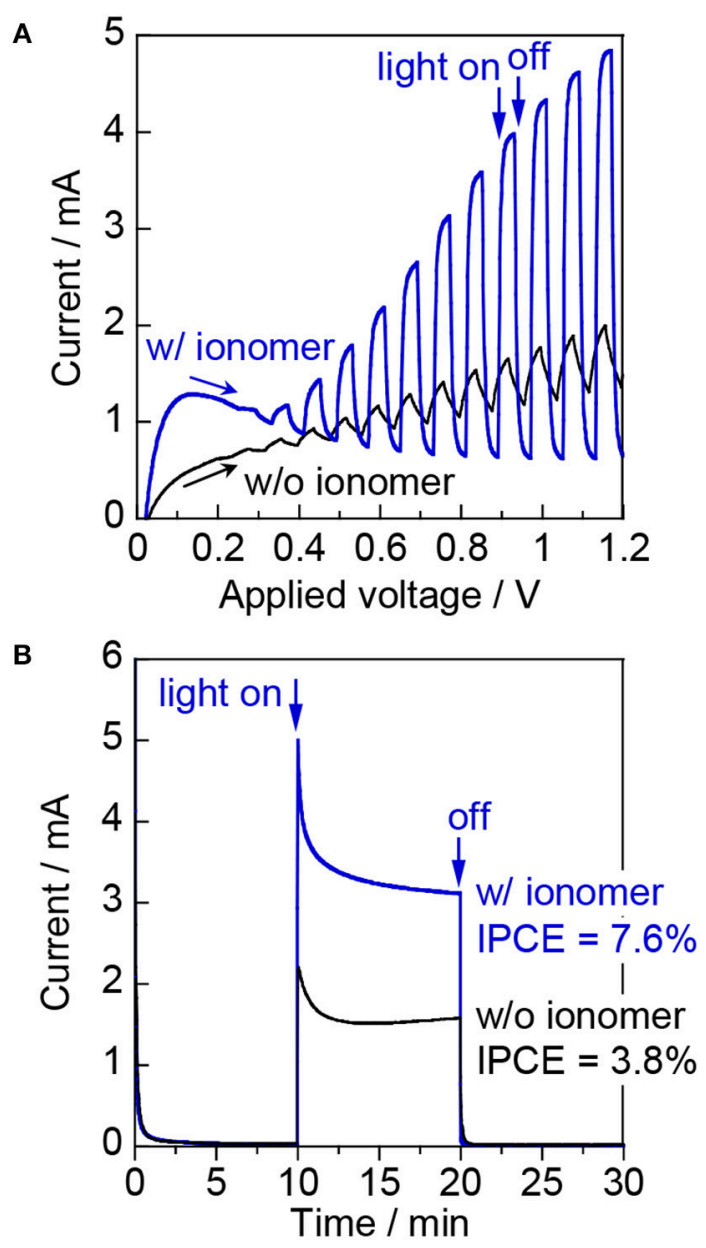

FIGURE 3 | (A) Linear sweep voltammetry curves at a scan rate of $20 \mathrm{mV} \mathrm{s}^{-1}$ under chopped irradiation ( $2 \mathrm{~s}$ intervals) and (B) current-time curves at an applied voltage of $1.2 \mathrm{~V}$ for $\mathrm{WO}_{3} / \mathrm{Ti}$ fiber electrodes with and without the Nafion ionomer coating. Reaction conditions: $453 \mathrm{~nm}$ blue light, irradiance: 6.8 $\mathrm{mW} \mathrm{cm}{ }^{-2}$, photoirradiation area: $16 \mathrm{~cm}^{2}, \mathrm{Ar} / \mathrm{H}_{2} \mathrm{O}=97 / 3$, flow rate to each electrode: $20 \mathrm{~mL} \mathrm{~min}^{-1}$.

electrons in the conduction band of $\mathrm{WO}_{3}$ are transported via the outer circuit to the counter electrode to reduce protons and evolve $\mathrm{H}_{2}$. The visible-light-induced $\mathrm{H}_{2}$ production rate was $\sim 1.0 \mu \mathrm{mol} \mathrm{min} \mathrm{m}^{-1}$.

In the second run, we analyzed the gas in the photoanode compartment. Although we confirmed that $\mathrm{O}_{2}$ evolution occurred under photoirradiation, the $\mathrm{O}_{2}$ formation rate was less than a quarter of the electron flow $\left(\mathrm{e}^{-} / 4\right)$. It should be noted that the formation rate shows a net increase of $\mathrm{O}_{2}$ because a small amount of $\mathrm{O}_{2}$ was mixed in the flow from the ambient air. When the light was turned on, we observed an initial decrease in the $\mathrm{O}_{2}$ concentration for the bare $\mathrm{WO}_{3} / \mathrm{Ti}$ fiber photoanode, likely because the $\mathrm{O}_{2}$ contaminant was consumed by a process such as photoabsorption under photoirradiation. The $\mathrm{O}_{2}$ evolution rate gradually increased with the $\mathrm{PEC}$ reaction, but the $\mathrm{FE}$ of $\mathrm{O}_{2}$ evolution was only $47 \%$, even just before turning off the light. As the FE was calculated by assuming that four
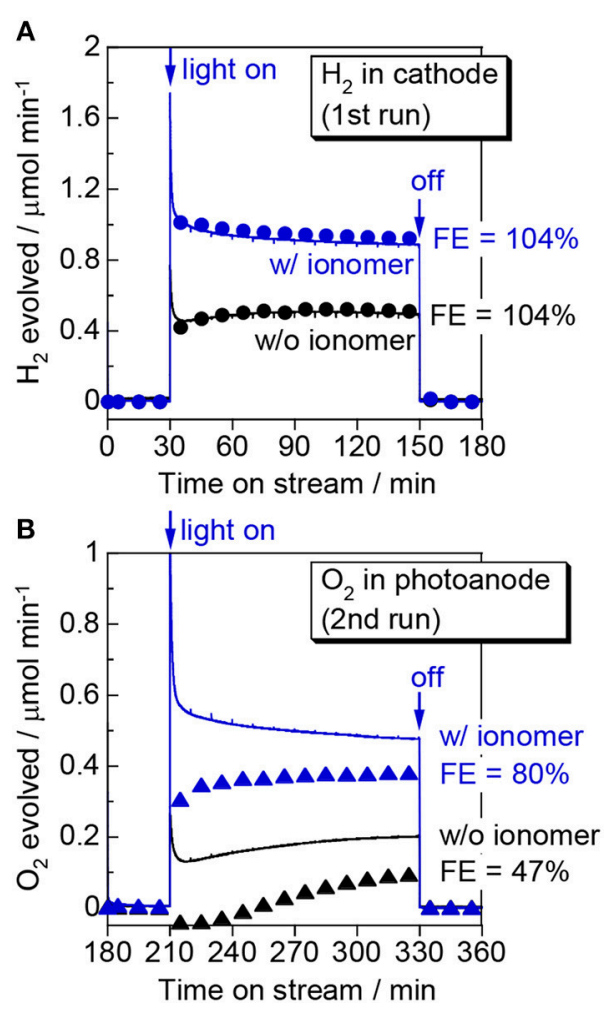

FIGURE 4 | Time course of $\mathbf{( A )} \mathrm{H}_{2}$ evolution in the first run and (B) $\mathrm{O}_{2}$ evolution in the second run during gas-phase water splitting over $\mathrm{WO}_{3} /$ Ti fiber photoelectrodes with and without a Nafion ionomer coating. We measured the $\mathrm{H}_{2}$ evolved in the cathode compartment in the first run and the $\mathrm{O}_{2}$ evolved in the photoanode compartment in the second run. The symbols show the product formation rate determined by gas chromatography and the curves show the electron flow passing through the outer circuit $\left(\mathrm{e}^{-} / 2\right.$ for $\mathrm{H}_{2}$ and $\mathrm{e}^{-} / 4$ for $\mathrm{O}_{2}$ ). Reaction conditions: $453 \mathrm{~nm}$ blue light, irradiance: $6.8 \mathrm{~mW} \mathrm{~cm}^{-2}$, photoirradiation area: $16 \mathrm{~cm}^{2}$, applied voltage: $1.2 \mathrm{~V}, \mathrm{Ar} / \mathrm{H}_{2} \mathrm{O}=97 / 3$, flow rate to each electrode: $20 \mathrm{~mL} \mathrm{~min}^{-1}$, temperature: $298 \mathrm{~K}$, pressure: $0.1 \mathrm{MPa}$.

electrons are required for the $\mathrm{O}_{2}$ evolution reaction, an $\mathrm{FE}$ of $<100 \%$ indicates the presence of byproducts such as hydrogen peroxide in the photoanode compartment. The formation of hydrogen peroxide via a reaction requiring two electrons was reported for a PEC reaction over a $\mathrm{WO}_{3}$ photoanode in an aqueous electrolyte (Santato et al., 2001). In contrast, the Nafion ionomer coating significantly enhanced the $\mathrm{FE}$ of $\mathrm{O}_{2}$ evolution up to $80 \%$. This result suggests that the proton-conducting thin film promoted the four-electron water oxidation reaction to evolve $\mathrm{O}_{2}$. The visible-light-induced $\mathrm{O}_{2}$ production rate with

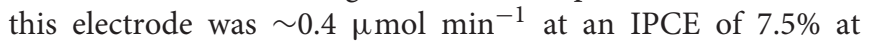
$1.2 \mathrm{~V}$.

Figure 5 shows a proposed schematic mechanism for water vapor oxidation over the ionomer-coated $\mathrm{WO}_{3} / \mathrm{Ti}$ fiber photoanode. The $\mathrm{O}_{2}$ evolution reaction $\left(2 \mathrm{H}_{2} \mathrm{O} \rightarrow \mathrm{O}_{2}+4 \mathrm{H}^{+}+\right.$ $4 \mathrm{e}^{-}$) is recognized as a proton-coupled electron transfer process (Surendranath et al., 2010; Warren et al., 2010). Photocatalysis processes over $\mathrm{TiO}_{2}$ and $\mathrm{ZnO}$ have also been confirmed as proton-coupled electron transfer reactions (Schrauben et al., 2012). The photogenerated holes in the valence band induce 
A

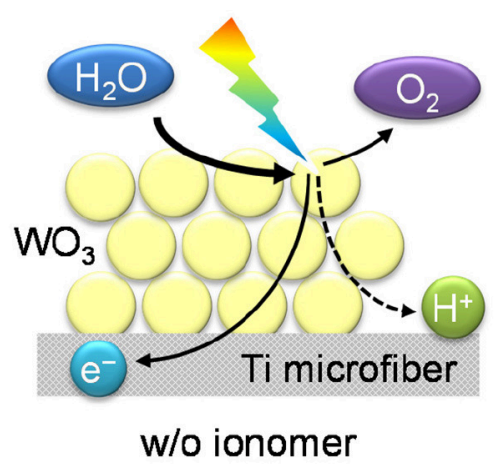

B

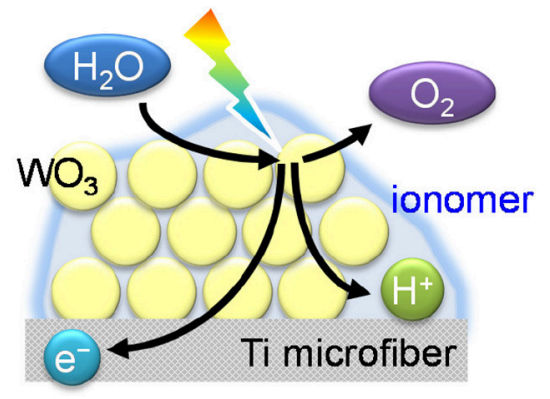

w/ ionomer

FIGURE 5 | Schematic illustrations of (A) the interfaces of the $\mathrm{WO}_{3} /$ Ti fiber electrode without the ionomer coating and $(\mathbf{B})$ the photoelectrochemical triple phase boundary of the ionomer-coated $\mathrm{WO}_{3} / \mathrm{Ti}$ fiber electrode.

four-electron oxidation of water to evolve $\mathrm{O}_{2}$. The concerted transfer process enhances the reaction rate because the transfer of multiple electrons and protons at the same time avoids the formation of the high-energy intermediates obtained during stepwise reactions. However, proton transfer at the gas-solid interface will be difficult in the absence of an aqueous electrolyte, which acts as an ion conductor. Therefore, the proton-coupled electron transfer is the rate-determining step of water vapor oxidation over the bare $\mathrm{WO}_{3} / \mathrm{Ti}$ fiber electrode. However, we found that the proton-conducting ionomer thin film promotes the gas-phase PEC reaction over the $\mathrm{WO}_{3} / \mathrm{Ti}$ fiber electrode. These results clearly indicate the importance of the gaselectrolyte-solid triple phase boundary for the PEC water vapor splitting reaction.

\section{PEC Measurements in the Three-Electrode Configuration}

We aimed to investigate the role of the triple phase boundary on the gas-phase PEC reactions. A small H-type glass cell (irradiated area: $1.0 \mathrm{~cm}^{2}$ ) was used to compare the PEC performance under different conditions. Figure 6 shows the setup for the PEC measurements in the three-electrode configuration using a platinum wire counter electrode and a $\mathrm{Ag} / \mathrm{AgCl}$ reference electrode. The two compartments were separated by a Nafion membrane. We filled the cathode compartment with an
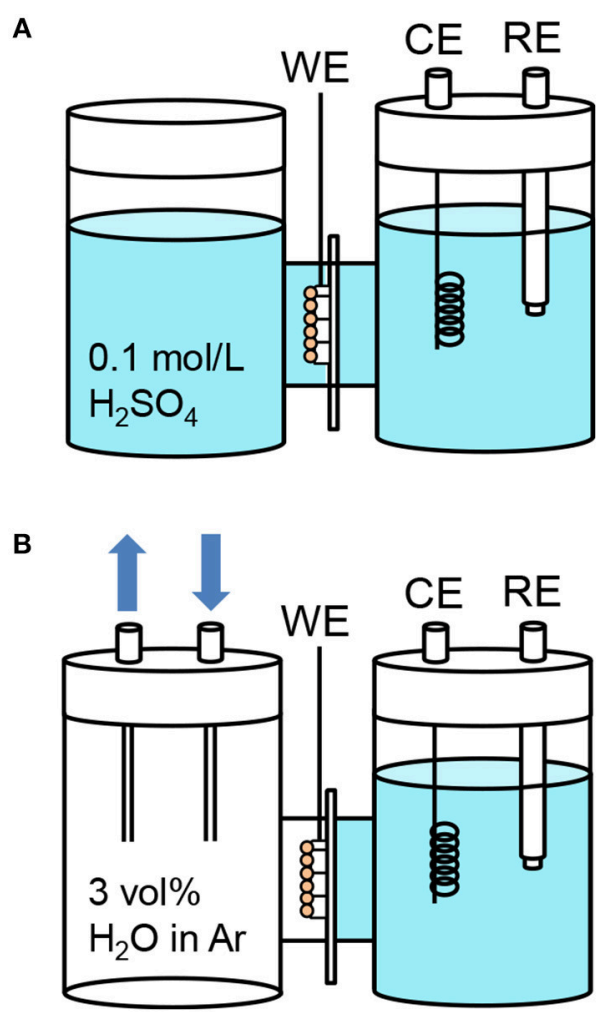

FIGURE 6 | Schematic illustrations of the $\mathrm{H}$-type dual compartment glass reactors used for testing the PEC performance of (A) "liquid | solid | liquid" interfaces and (B) "gas | solid | liquid" interfaces in the three-electrode configuration. (WE: $1 \mathrm{~cm}^{2}$ working electrode pressed on a Nafion membrane, $\mathrm{CE}$ : Pt counter electrode, $\mathrm{RE}, \mathrm{Ag} / \mathrm{AgCl}$ reference electrode). The gas flow was argon with 3 vol\% water vapor. The aqueous electrolyte was $0.1 \mathrm{~mol} \mathrm{~L}^{-1}$ sulfuric acid $(\mathrm{pH}=1)$.

aqueous electrolyte to maintain electrical neutrality between the membrane, the counter electrode, and the reference electrode. The $\mathrm{WO}_{3} / \mathrm{Ti}$ fiber photoanode, which was in contact with the Nafion membrane, was exposed to the other compartment. We investigated two different photoanode conditions. In the first, the photoanode was immersed in an aqueous electrolyte (Figure 6A), whereas in the second, the photoanode was exposed to an argon flow with 3 vol\% water vapor (Figure 6B). These setups are denoted as "liquid | solid | liquid" and "gas | solid | liquid" interfaces, respectively.

Figure 7A shows the photocurrent density at $1.0 \mathrm{~V}$ vs. $\mathrm{Ag} / \mathrm{AgCl}$ for the "liquid | solid | liquid" interfaces. The photocurrent exhibited by the bare electrode was higher than that of the ionomer-coated electrode during the liquid-phase water splitting reaction. This observation indicates that the Nafion ionomer coating retards the oxidation of water, probably by interrupting water adsorption and/or $\mathrm{O}_{2}$ desorption on the $\mathrm{WO}_{3}$ surface. Figure $7 \mathbf{B}$ shows the photocurrent density at $1.0 \mathrm{~V}$ vs. $\mathrm{Ag} / \mathrm{AgCl}$ for the "gas | solid | liquid" interfaces. The IPCE decreased from 28.1 to $10.7 \%$ when the photoanode cell was changed from the liquid phase to the two-phase environment. This decrease indicates that the penetration of 

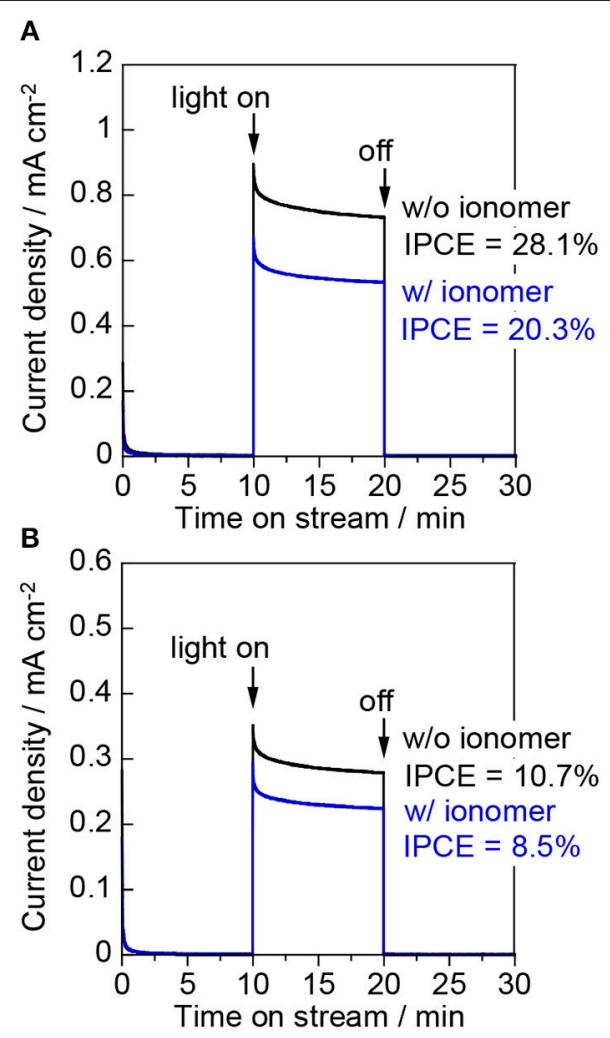

FIGURE 7 | Current-time curves of (A) the "liquid | solid | liquid" interfaces and (B) the "gas | solid | liquid" interfaces at an applied potential of $1.0 \mathrm{~V}$ vs. $\mathrm{Ag} / \mathrm{AgCl}$ in a three-electrode configuration. The working electrodes were $\mathrm{WO}_{3} / \mathrm{Ti}$ fiber electrodes with and without a Nafion ionomer coating. The irradiation source was $453 \mathrm{~nm}$ blue light.
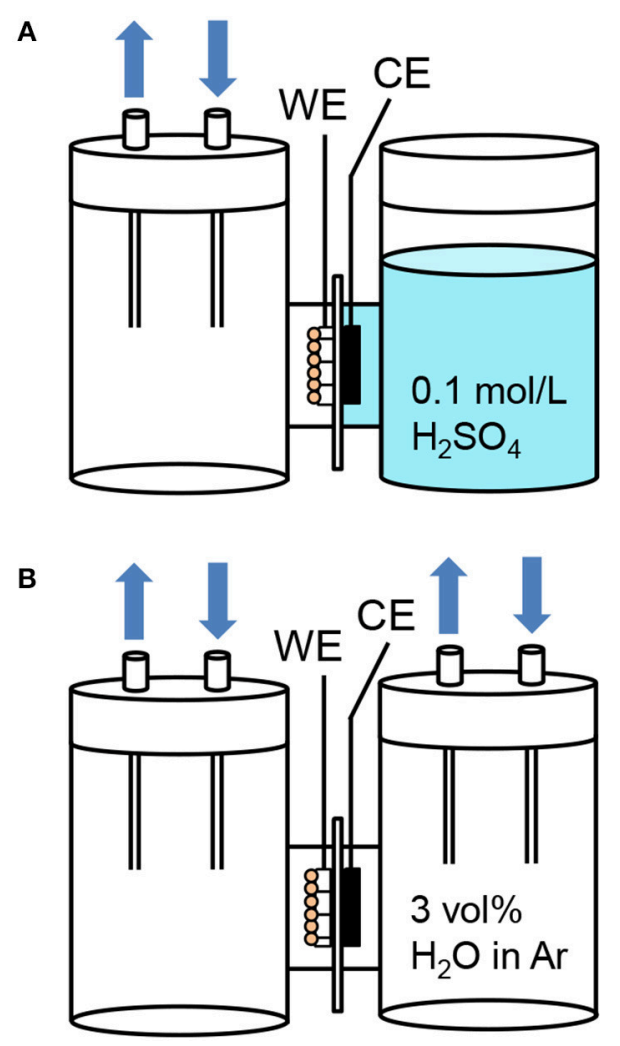

FIGURE 8 | Schematic illustrations of the H-type dual compartment glass reactors using for testing the PEC performance of (A) "gas | solid | liquid" interfaces and (B) "gas | solid | gas" interfaces in the two-electrode configuration. (WE: $1 \mathrm{~cm}^{2}$ working electrode pressed on a Nafion membrane, CE: ionomer-mixed Pt/CB electrode on the opposite side of the membrane). the aqueous electrolyte into the interconnected mesopores of the $\mathrm{WO}_{3}$ nanoparticles is very important for enhancing the proton-coupled electron transfer process during water oxidation. The photocurrent of the bare electrode decreased more than that of the ionomer-coated electrode when the liquid phase was changed for the two-phase environment. However, the photocurrent of the bare electrode was still higher than that of the ionomer-coated electrode. This is because the Nafion membrane remained fully hydrated when one part of it was in contact with the aqueous electrolyte in the other compartment. Therefore, the bare $\mathrm{WO}_{3}$ electrode was also coated with a thin layer of the aqueous electrolyte because it was in contact with the wetted Nafion membrane.

\section{PEC Measurements in the Two-Electrode Configuration}

We further investigated the PEC performance of the $\mathrm{WO}_{3} / \mathrm{Ti}$ fiber photoanodes in the two-electrode configuration to compare two different cathode conditions as shown in Figure 8. The ionomer-mixed Pt/CB film was used as a counter electrode in place of the platinum wire in the three-electrode configuration. The $\mathrm{WO}_{3} / \mathrm{Ti}$ fiber and the ionomer-mixed $\mathrm{Pt} / \mathrm{CB}$ film were in contact with a Nafion membrane. For the "gas | solid | liquid" interfaces, the $\mathrm{WO}_{3} / \mathrm{Ti}$ fiber photoanode was exposed to the gas phase and the ionomer-mixed $\mathrm{Pt} / \mathrm{CB}$ cathode was immersed in an aqueous electrolyte (Figure 8A). For the "gas | solid | gas" interfaces, both the photoanode and the cathode were exposed to the gas phase (Figure 8B). The electrode potential of $1.0 \mathrm{~V}$ vs. $\mathrm{Ag} / \mathrm{AgCl}$ at $\mathrm{pH}=1$ corresponds to $1.25 \mathrm{~V}$ vs. RHE. Therefore, we set the applied voltage to $1.20 \mathrm{~V}$ in the two-electrode configuration.

Figure 9A shows the results for the "gas | solid | liquid" interfaces in the two-electrode system. The photocurrent densities at an applied voltage of $1.2 \mathrm{~V}$ were similar to those at $1.0 \mathrm{~V}$ vs. $\mathrm{Ag} / \mathrm{AgCl}$ in the three-electrode configuration. This result indicates that the cathodic polarization distributed from the applied voltage was small on the ionomer-mixed $\mathrm{Pt} / \mathrm{CB}$ catalyst electrode owing to the low overpotential for the $\mathrm{H}_{2}$ evolution reaction. The performance of a polymer electrolyte fuel cell is significantly increased by a good network of the perfluorosulfonate ionomers contacting with Pt nanoparticles (Uchida et al., 1995). The ionomer is also necessary to prepare the viscous catalyst ink for the Pt/CB catalyst layer with good bonding. Figure 9B shows the photocurrent density at the "gas | solid | gas" interfaces in the two-electrode system. The IPCE of the bare $\mathrm{WO}_{3} / \mathrm{Ti}$ fiber decreased from 8.2 to 
A

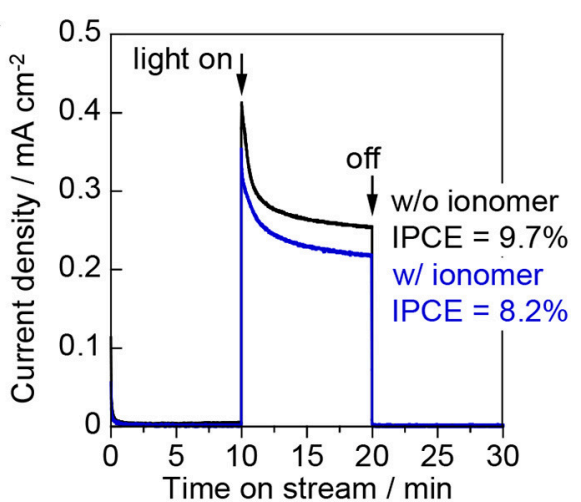

B

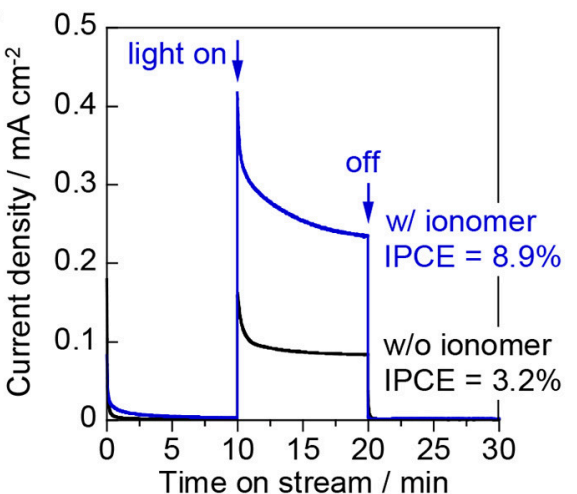

FIGURE 9 | Current-time curves of (A) the "gas | solid | liquid" interfaces and (B) the "gas | solid | gas" interfaces at an applied voltage of $1.2 \mathrm{~V}$ in the two-electrode configuration. The working electrodes were $\mathrm{WO}_{3} / \mathrm{Ti}$ fiber electrodes with and without a Nafion ionomer coating. The irradiation source was $453 \mathrm{~nm}$ blue light.

$3.2 \%$ by changing from the two-phase condition to the gasphase condition. In contrast, the photocurrent densities of the ionomer-coated $\mathrm{WO}_{3} / \mathrm{Ti}$ fiber were the same for the "gas $\mid$ solid | liquid" and the "gas | solid | gas" interfaces. As a result, the IPCE of the ionomer-coated $\mathrm{WO}_{3} / \mathrm{Ti}$ fiber was $180 \%$ higher than that of the bare $\mathrm{WO}_{3} / \mathrm{Ti}$ fiber electrode in the gas-phase PEC reaction.

Figure 10 shows the IPCE action spectrum of the ionomercoated $\mathrm{WO}_{3} /$ Ti fiber electrode in the "gas | solid | liquid" interfaces. A visible-light response was observed at $\sim 460 \mathrm{~nm}$, which is consistent with the optical band gap of monoclinic $\mathrm{WO}_{3}$ nanoparticles $(2.67 \mathrm{eV})$ estimated from the Tauc plot of the diffuse reflectance spectrum (Amano et al., 2017). In this study, the photocurrent response was investigated under blue light irradiation at $453 \mathrm{~nm}$, which is very close to the threshold wavelength. This is the reason for the relatively low IPCE values under blue light. We found that the IPCE at $1.0 \mathrm{~V}$ vs. $\mathrm{Ag} / \mathrm{AgCl}$ was higher than $40 \%$ under UV irradiation at wavelengths $<400 \mathrm{~nm}$. Moreover, the IPCE value was much higher than that of an ionomer-coated $\mathrm{TiO}_{2} / \mathrm{Ti}$ fiber (IPCE $=26 \%$ at $1.2 \mathrm{~V}$ under $365 \mathrm{~nm}$ UV irradiation) for gas-phase water oxidation (Amano et al., in press). To the best of our knowledge, this IPCE value is the highest among those reported for photoanodes in PEM-PEC systems.

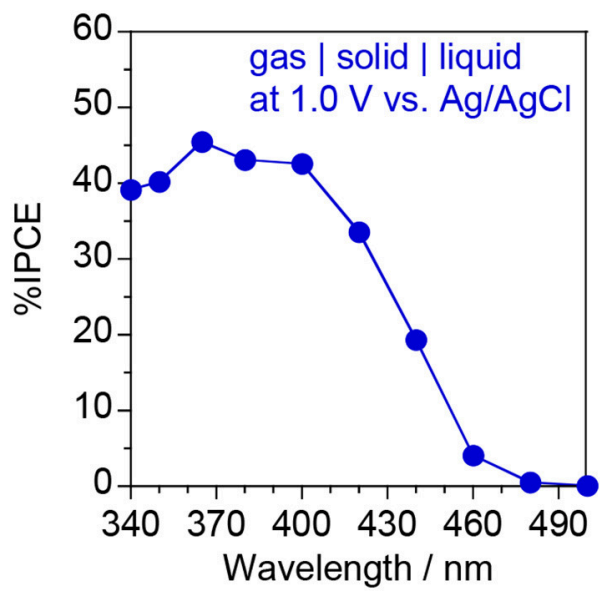

FIGURE 10 | IPCE action spectrum of the ionomer-coated $\mathrm{WO}_{3} / \mathrm{Ti}$ fiber photoanode at $1.0 \mathrm{~V}$ vs. $\mathrm{Ag} / \mathrm{AgCl}$ using the "gas | solid | liquid" interfaces shown in Figure 8A

\section{DISCUSSION}

We found that a proton-conducting ionomer coating enhanced the PEC oxidation of water in the gas phase, although this effect was not observed in aqueous media. The IPCE of the bare $\mathrm{WO}_{3} /$ Ti fiber decreased from $28.1 \%$ in the liquid phase to $9.7-$ $10.7 \%$ in the two-phase system and to $3.2 \%$ in the gas phase. This behavior indicates that an aqueous electrolyte is essential for $\mathrm{PEC}$ reactions that involve proton-coupled electron transfer. In the case of the gas-phase PEC reaction, the hydrated Nafion ionomer thin film plays the role of a solid electrolyte with good proton conductivity at room temperature. The ionomer coating also can absorb water molecules from the gas phase to enhance the hydration of the electrode surface. The Nafion ionomer membrane must be hydrated to maintain the high proton conductivity (Spurgeon and Lewis, 2011). The investigation of the $\mathrm{PEC}$ reaction in aqueous media revealed that the ionomer thin film slightly retards the transport of materials, which affects water adsorption and/or $\mathrm{O}_{2}$ desorption on the $\mathrm{WO}_{3}$ surface. However, the gas permeability of the thin film is sufficient to create a gas-electrolyte-solid triple phase boundary, where gaseous reactants and products are accessible.

Recently, we found that $\mathrm{TiO}_{2}$ electrodes without a Nafion ionomer coating exhibit negligible photocurrents for the PEC oxidation of gas-phase water vapor (Amano et al., in press). In contrast, the bare $\mathrm{WO}_{3} / \mathrm{Ti}$ fiber electrode exhibited a moderate photocurrent density during the gas-phase PEC reaction. This difference in behavior can be attributed to the proton conductivity of the oxide surfaces. The Nafion ionomer is a perfluorosulfonic acid with strong acidity, and $\mathrm{WO}_{3}$ is an acidic oxide with an isoelectric point at $\mathrm{pH} 1.5$ (Anik and Cansizoglu, 2006). In contrast, $\mathrm{TiO}_{2}$ is a neutral oxide with an isoelectric point at pH 5-7 (Maeda and Domen, 2010). Thus, the acidic nature of the $\mathrm{WO}_{3}$ surface can slightly promote proton transport at room temperature. However, the proton conductivity of the bare electrode was not sufficient for the gas-phase PEC reaction. 
The Nafion ionomer coating enhanced the photocurrent density for the oxidation of water vapor to evolve $\mathrm{O}_{2}$. The $\mathrm{FE}$ of $\mathrm{O}_{2}$ evolution was enhanced to $80 \%$, suggesting that the majority of the photogenerated holes were consumed by a four-electron reaction involving proton-coupled electron transfer.

The fabricated PEM-PEC cell shows a $\mathrm{H}_{2}$ evolution rate of $\sim 1.0 \mu \mathrm{mol} \mathrm{min}{ }^{-1}$ at $1.2 \mathrm{~V}$ under visible-light irradiation $(\lambda=$ $453 \mathrm{~nm}, I_{0}=6.8 \mathrm{~mW} \mathrm{~cm}^{-2}$ ). The rate of $\mathrm{H}_{2}$ evolution was much higher than that of the previously reported PEM-PEC systems (Stoll et al., 2016, 2017). The IPCE of $40 \%$ in the UV range was also the highest value in the gas-phase water photoelectrolysis reaction. This work highlights that the gas-electrolyte-solid triple phase boundary sustained by solid polymer electrolyte plays a significant role in enhancing the photocurrent in the absence of liquid water. To implement solar water splitting technologies, it is necessary to decrease the applied bias voltage and increase the IPCE in the visible light region.

In conclusion, we have successfully fabricated a PEC system consisting of $\mathrm{WO}_{3}$ nanoparticles for water vapor splitting under visible-light irradiation. A high-surface-area $\mathrm{WO}_{3} /$ Ti fiber gas diffusion electrode was coated with a perfluorosulfonate electrolyte thin film to improve the proton conductivity. Under

\section{REFERENCES}

Abe, R. (2010). Recent progress on photocatalytic and photoelectrochemical water splitting under visible light irradiation. J. Photochem. Photobiol. C 11, 179-209. doi: 10.1016/j.jphotochemrev.2011.02.003

Amano, F., Ishinaga, E., and Yamakata, A. (2013). Effect of particle size on the photocatalytic activity of $\mathrm{WO}_{3}$ particles for water oxidation. J. Phys. Chem. C 117, 22584-22590. doi: 10.1021/jp408446u

Amano, F., Mukohara, H., Shintani, A., and Tsurui, K. (in press). Solid polymer electrolyte-coated titania nanotube macroporous photoelectrode for gas-phase water splitting. ChemSusChem. doi: 10.1002/cssc.201802178

Amano, F., Shintani, A., Tsurui, K., and Hwang, Y.-M. (2017). Fabrication of tungsten trioxide photoanode with titanium microfibers as a three dimensional conductive back contact. Mater. Lett. 199, 68-71. doi: 10.1016/j.matlet.2017.04.051

Anik, M., and Cansizoglu, T. (2006). Dissolution kinetics of $\mathrm{WO}_{3}$ in acidic solutions. J. Appl. Electrochem. 36, 603-608. doi: 10.1007/s10800-0069113-3

Georgieva, J., Armyanov, S., Poulios, I., Jannakoudakis, A. D., and Sotiropoulos, S. (2010). Gas phase photoelectrochemistry in a polymer electrolyte cell with a titanium dioxide/carbon/nafion photoanode. Electrochem. Solid State Lett. 13, P11-P13. doi: 10.1149/1.3465306

Georgieva, J., Armyanov, S., Poulios, I., and Sotiropoulos, S. (2009). An all-solid photoelectrochemical cell for the photooxidation of organic vapours under ultraviolet and visible light illumination. Electrochem. Commun. 11, 1643-1646. doi: 10.1016/j.elecom.2009.06.019

Hisatomi, T., Takanabe, K., and Domen, K. (2015). Photocatalytic water-splitting reaction from catalytic and kinetic perspectives. Catal. Lett. 145, 95-108. doi: 10.1007/s10562-014-1397-z

Homura, H., Ohtani, B., and Abe, R. (2014). Facile fabrication of photoanodes of tungsten(VI) oxide on carbon microfiber felts for efficient water oxidation under visible light. Chem. Lett. 43, 1195-1197. doi: 10.1246/cl.140320

Iwu, K. O., Galeckas, A., Kuznetsov, A. Y., and Naorby, T. (2013). Solid-state photoelectrochemical $\mathrm{H} 2$ generation with gaseous reactants. Electrochim. Acta 97, 320-325. doi: 10.1016/j.electacta.2013.03.013

Kumari, S., Turner White, R., Kumar, B., and Spurgeon, J. M. (2016). Solar hydrogen production from seawater vapor electrolysis. Energy Environ. Sci. 9, 1725-1733. doi: 10.1039/c5ee03568f gas-phase conditions, the ionomer coating significantly enhanced the IPCE as well as the current efficiency of the $\mathrm{O}_{2}$ evolution reaction by four-electron oxidation of water vapor. The gaselectrolyte-solid triple phase boundary on the high-surface-area photoanode enhanced the extent of proton-coupled electron transfer between the photogenerated holes and the adsorbed water, which was fed from the gas phase. The concept provides insights into the features necessary for successful gas-phase operation, which is a promising approach for low-cost, largescale $\mathrm{H}_{2}$ production under solar irradiation.

\section{AUTHOR CONTRIBUTIONS}

FA designed and guided the study and wrote the paper; AS, $\mathrm{HM}, \mathrm{Y}-\mathrm{MH}$, and KT carried out experiments and analyzed the data.

\section{ACKNOWLEDGMENTS}

This work was supported by the JST, Precursory Research for Embryonic Science and Technology (PRESTO), grant number JPMJPR15S1 and JPMJPR18T1.

Kusoglu, A., and Weber, A. Z. (2017). New insights into perfluorinated sulfonicacid ionomers. Chem. Rev. 117, 987-1104. doi: 10.1021/acs.chemrev.6b00159

Maeda, K., and Domen, K. (2010). Photocatalytic water splitting: recent progress and future challenges. J. Phys. Chem. Lett. 1, 2655-2661. doi: 10.1021/jz1007966

McKone, J. R., Lewis, N. S., and Gray, H. B. (2014). Will solar-driven water-splitting devices see the light of day? Chem. Mater. 26, 407-414. doi: 10.1021/cm4021518

Modestino, M. A., Dumortier, M., Hosseini Hashemi, S. M., Haussener, S., Moser, C., and Psaltis, D. (2015). Vapor-fed microfluidic hydrogen generator. Lab Chip 15, 2287-2296. doi: 10.1039/c5lc00259a

Pinaud, B. A., Benck, J. D., Seitz, L. C., Forman, A. J., Chen, Z., Deutsch, T. G., et al. (2013). Technical and economic feasibility of centralized facilities for solar hydrogen production via photocatalysis and photoelectrochemistry. Energy Environ. Sci. 6, 1983-2002. doi: 10.1039/c3ee40831k

Rongé, J., Deng, S., Pulinthanathu Sree, S., Bosserez, T., Verbruggen, S. W., Kumar Singh, N., et al. (2014). Air-based photoelectrochemical cell capturing water molecules from ambient air for hydrogen production. RSC Adv. 4, 29286-29290. doi: 10.1039/c4ra05371k

Rongé, J., Nijs, D., Kerkhofs, S., Masschaele, K., and Martens, J. A. (2013). Chronoamperometric study of membrane electrode assembly operation in continuous flow photoelectrochemical water splitting. Phys. Chem. Chem. Phys. 15, 9315-9325. doi: 10.1039/c3cp50890k

Santato, C., Ulmann, M., and Àugustynski, J. (2001). Photoelectrochemical properties of nanostructured tungsten trioxide films. J. Phys. Chem. B 105, 936-940. doi: 10.1021/jp002232q

Schrauben, J. N., Hayoun, R., Valdez, C. N., Braten, M., Fridley, L., and Mayer, J. M. (2012). Titanium and zinc oxide nanoparticles are proton-coupled electron transfer agents. Science 336, 1298-1301. doi: 10.1126/science.1220234

Spurgeon, J. M., and Lewis, N. S. (2011). Proton exchange membrane electrolysis sustained by water vapor. Energy Environ. Sci. 4, 2993-2998. doi: $10.1039 / \mathrm{clee} 01203 \mathrm{~g}$

Stoll, T., Zafeiropoulos, G., Dogan, I., Genuit, H., Lavrijsen, R., Koopmans, B., et al. (2017). Visible-light-promoted gas-phase water splitting using porous $\mathrm{WO}_{3} / \mathrm{BiVO}_{4}$ photoanodes. Electrochem. Commun. 82, 47-51. doi: 10.1016/j.elecom.2017.07.019

Stoll, T., Zafeiropoulos, G., and Tsampas, M. N. (2016). Solar fuel production in a novel polymeric electrolyte membrane photoelectrochemical (PEM-PEC) cell with a web of titania nanotube arrays as photoanode and gaseous reactants. Int. J. Hydrogen Energy 41, 17807-17817. doi: 10.1016/j.ijhydene.2016.07.230 
Surendranath, Y., Kanan, M. W., and Nocera, D. G. (2010). Mechanistic studies of the oxygen evolution reaction by a cobalt-phosphate catalyst at neutral pH. J. Am. Chem. Soc. 132, 16501-16509. doi: 10.1021/ ja106102b

Tsui, L.-K., Homma, T., and Zangari, G. (2013). Photocurrent conversion in anodized $\mathrm{TiO}_{2}$ nanotube arrays: effect of the water content in anodizing solutions. J. Phys. Chem. C 117, 6979-6989. doi: 10.1021/ jp400318n

Uchida, M., Aoyama, Y., Eda, N., and Ohta, A. (1995). Investigation of the microstructure in the catalyst layer and effects of both perfluorosulfonate lonomer and PTFE-loaded carbon on the catalyst layer of polymer electrolyte fuel cells. J. Electrochem. Soc. 142, 4143-4149. doi: 10.1149/1. 2048477

Verbruggen, S. W., Van Hal, M., Bosserez, T., Rongé, J., Hauchecorne, B., Martens, J. A., et al. (2017). Harvesting hydrogen gas from air pollutants with an unbiased gas phase photoelectrochemical cell. ChemSusChem 10, 1413-1418. doi: 10.1002/cssc.2016 01806
Warren, J. J., Tronic, T. A., and Mayer, J. M. (2010). Thermochemistry of proton-coupled electron transfer reagents and its implications. Chem. Rev. 110, 6961-7001. doi: 10.1021/cr100085k

Xiang, C., Weber, A. Z., Ardo, S., Berger, A., Chen, Y., Coridan, R., et al. (2016). Modeling, simulation, and implementation of solar-driven water-splitting devices. Angew. Chem. Int. Ed. 55, 12974-12988. doi: 10.1002/anie.201510463

Conflict of Interest Statement: The authors declare that the research was conducted in the absence of any commercial or financial relationships that could be construed as a potential conflict of interest.

Copyright (c) 2018 Amano, Shintani, Mukohara, Hwang and Tsurui. This is an open-access article distributed under the terms of the Creative Commons Attribution License (CC BY). The use, distribution or reproduction in other forums is permitted, provided the original author(s) and the copyright owner(s) are credited and that the original publication in this journal is cited, in accordance with accepted academic practice. No use, distribution or reproduction is permitted which does not comply with these terms. 